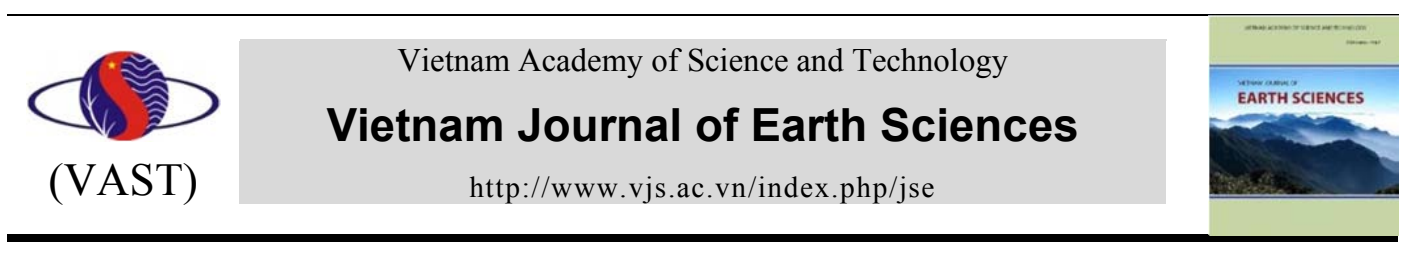

\title{
Empirical Attenuation relationship for Peak Ground Horizontal Acceleration for North-East Himalaya
}

\author{
Arjun Kumar1*, Himanshu Mittal², Rohtash Kumar³, Rajeev Saran Ahluwalia ${ }^{4}$ \\ ${ }^{1}$ Department of Civil Engineering Arni University, Kathgarh, (H.P), India \\ ²207, Back suit, Global Change Center National Taiwan University, No. 1, Roosevelt Rd., Sec. 4, Taipei-10617 \\ ${ }^{3}$ Department of Geophysics Banaras Hindu University, Varanasi, India \\ ${ }^{4}$ Centre for Glaciology, Wadia Institute of Himalayan Geology, Dehradun (U.K.) India
}

Received 30 August 2016. Accepted 6 February 2017

\begin{abstract}
North-East India is located in one of the most seismic prone areas of the world. India has faced several devastating earthquakes in the past. The largest of these have originated in the Himalayan plate boundary region, which has remained a region of great scientific and engineering interest. In spite of this, very little seismological information is available about North- East India, which is the focus for present study. Only few attenuation relationships are available for this region, which are most valuable in a region where too much strong motion recordings are not available. However in recent time, with the inception of 300 strong motion instruments under Indian National Strong Motion Network deployed under Mission Mode project (Government of India), a good quality of strong motion data became available. Taking the advantage of data collected by this network and earlier analogue strong motion arrays, an endeavor has been made to develop an empirical attenuation relationship for peak horizontal ground accelerations for North-East Himalayan region in India. The data set consists of 216 peak ground horizontal accelerations from 24 earthquakes $(4.0 \leq \mathrm{M} \leq 6.8)$ recorded by strong-motion arrays and National Strong Motion Network project in India. The present analysis uses a two-step stratified regression model. The estimated attenuation relationship for the region is

$$
\log (A)=-1.497+0.3882 M-1.19 \log \left(X+e^{0.2876 M}\right)
$$

Where $\mathrm{A}$ is the peak ground acceleration ( $\mathrm{g}$ ), $\mathrm{M}$ is the magnitude, and $\mathrm{X}$ is the hypocentral distance from the source. The residual sum of squares is 0.1451 . The obtained Empirical attenuation relationship will provide better insight for site specific studies as well as for hazard estimation for North-East Himalayan region. Attenuation relationships for expected peak ground acceleration (g) have been presented for magnitudes 5, 6, 7 and 8 for North-East Himalayan region.
\end{abstract}

Keywords: Empirical, attenuation, regression, mission-mode, North-East Himalaya.

(C)2017 Vietnam Academy of Science and Technology

\section{Introduction}

The collision of the Indian tectonic plate

"Corresponding author, Email: arjundeq@gmail.com with the Eurasian Plate creates wonderful arc shaped Himalayan mountain ranges that extend from west-northwest to east-southeast These mountain ranges have length of about 
Arjun Kumar, et al./Vietnam Journal of Earth Sciences 39 (2017)

2,400 kilometres; width varies from 400 kilometres in the west to 150 kilometres in the east and attained heights up to 7,200 metres. Many major rivers originate from the glaciers of the Himalaya and provide homage to more than 600 million people. This region has a great potential for hydropower generation, and a number of small to large-scale hydropower projects are either in operation or are in under construction. But the region is also challenged by high seismic activity. Several tectonic features of local and regional scale have been mapped in the region around. Many moderate to large sized earthquakes, have occurred in this region. The whole Himalayan region is seismically very active. Like the other parts of Himalaya, the north-eastern Himalaya exhibits quiet high seismicity and lies within the seismic zone IV and zone $\mathrm{V}$ as per IS Code (IS 1893 (Part 1): 2002). Several earthquakes of smaller to moderate magnitudes have occurred in this region (Verma et al., 1976; Mukhopadhayay, 1984; Kayal, 1987; Kumar et al., 2012, 2013a, b). The two great earthquakes namely Shillong (1897) and Assam (1950) earthquakes having magnitudes 8.1 and 8.6, respectively occurred in this region. Shillong earthquake on June 12, $1897(\mathrm{Mw},-8.1)$ was located near the northern edge of Shillong Plateau while Assam earthquake of August 15, 1950 was located in Mishmi hills. On September 18, 2011 the Sikkim earthquake of magnitude Mw 6.8 occurred in this region.

Earthquakes are one of the most unpredictable natural phenomena. As prediction of earthquakes is impossible now, only well engineered structures is the way to get safety. To reduce the loss of life and property, men have tried to estimate the level of ground shaking to which they may be subjected. Since the level of ground shaking is most commonly used in terms of ground motion parameters, methods for estimating ground motion parameters are required. The design of any engineered structures is based on the estimate of strong mo- tion, either implicitly through the use of building codes or explicitly in the site-specific design of large or particularly critical structures (Sharma, 2005). Ground Motion Prediction Equations (GMPEs) are used for the estimation of the ground motion parameters which are needed for the design and evaluation of important structures including the nuclear power plants, hydel projects, etc. The seismic hazard may contribute greatly to the total risk of a nuclear power plant. Therefore, the selection of appropriate GMPEs may have a great influence on the design and safety of a structure. Development of a predictive mathematical model, called Attenuation Relationship is necessary to predict strong ground motion necessary to carry out a comprehensive assessment of seismic hazard and risk to reduce the economic and social effects. The data to develop empirical attenuation relationships consists of accelerogram recorded from previous earthquakes in three orthogonal directions, longitudinal, transversal and vertical. Such relationships have been developed in the past for various regions, and comprehensive reviews have been published for such relationships (Boore and Joyner, 1982; Campbell, 1985; Joyner and Boore, 1988; Abrahamson and Litehiser, 1989; Fukushima and Tanaka, 1990; Sharma, 1998; Douglas 2001 etc.). Attenuation relationships have been mainly developed for peak ground acceleration and response spectra. GMPEs describe the variation of the median and lognormal standard deviation of intensity measures (such as peak acceleration, spectral acceleration, or duration) with magnitude, site-source distance, site condition, and other parameters (Kramer, 1996). Different combinations of horizontal components are used in different attenuation relationship, such as, larger component (Ambraseys \& Douglas, 2003), both components (Fukushima et al., 2003), geometric mean (Campbell \& Bozorgnia, 2003), randomly chosen component (Atkinson \& Boore, 2003), resolved component (Sun \& Peng, 1993) etc. 
Vietnam Journal of Earth Sciences, 39(1), 47-57

Most of the relationships are developed using worldwide acceleration data acquired through the strong-motion arrays. A number of attenuation relationships have been developed using the dataset of Indian earthquake (e.g. Aman et al., 1995; Singh et al., 1996; Sharma, 1998; Jain et al., 2000; Iyengar and Ghosh, 2004; Nath et al., 2012; Raghukanth and Kavitha, 2014). Most of the dataset have been taken from the Himalayan region. In the present work, the strong motion data from strongmotion arrays and mission mode projects have been used to develop empirical attenuation relationship for peak ground acceleration for North-East Himalayan, as only few attenuation relationships are available for this region.

\section{Seismotectonics and Seismicity}

The entire Indian subcontinent can be divided into three main sub-regions on the basis of general geological and tectonic features (Khattri et al. 1984). The first sub-region is formed by the Kirthar and Sulaiman mountain ranges in the northwest, the Himalayan Mountains in the north, extending from west to east for a distance of $2500 \mathrm{~km}$ and the Arakan Yoma mountain ranges in the east, extending from north to south into the island arc system of the Andaman Nicobar, Sumatra and Java Islands. The average elevation in this region lies between 1000 and $4500 \mathrm{~m}$.

The area covering the north-eastern part of India and northern Burma is one of the most interesting in the world from the viewpoint of tectonics. This area includes several prominent tectonic features such as the ArakanYoma, the Assam Valley, the Bengal basin, the Eastern Himalayas, the Irrawaddy basin, Naga Hills, Shillong Plateau, etc. The area lies approximately between latitude $20^{\circ} \mathrm{N}$ to $28^{\circ} \mathrm{N}$ and longitude $88^{\circ}$ to $98^{\circ} \mathrm{E}$ (Figure 1).

In northeastern India, large scale thrust movements have taken place from northwest and southeast directions resulting in crustal shortening estimated to be of the order of 150 to $300 \mathrm{~km}$ (Evans, 1964). In northern Burma, the movements have been mostly in the eastwest direction. These thrust movements have culminated in the formation of the northeast Himalaya in the north, Naga Hills to the southeast of Assam Valley, the folded belt of Tripura and Arakan-Yoma in northern Burma. Figure 1 shows the generalized tectonic map of India (Parvez et al., 2008).

Northeast India is seismically one of the six most active regions of the world, the other five being Mexico, Taiwan, California, Japan, and Turkey. It is placed in zone 5, the highest zone, of the seismic zonation map of India. It lies at the junction of the Himalayan arc to the north and Burmese arc to the east. The region has experienced 18 large earthquakes $(M \geq 7)$ during the last hundred years including the great earthquakes of Shillong $(1897, \mathrm{M}=8.7)$ and Assam-Tibet border (1950, M = 8.7). Besides, several hundred small and microearthquakes have also been recorded in the region. The high seismicity in the region is attributed to the collision tectonics between the Indian plate and the Eurasian plate in the north and subduction tectonics along the Indo-Myanmar range (IMR) in the east (Dewey and Bird 1970; Kayal, 1996, 1998). The high seismicity of the northeast Indian region has been attributed to a complex tectonic province displaying juxtaposition of the E-W trending the Himalaya and the N-S trending Arakan Yoma belt. The major tectonic background includes the eastern Himalayan structures, the Mishmi massif, the Indo-Myanmar arc, the Brahmaputra valley, and the Shillong plateau. The Himalayan structures mainly consist of the thrust planes namely the Main Central Thrust (MCT), Main Boundary thrust (MBT), Main Frontal Thrust (MFT), and their subsidiaries (Nandy 2001). The movement along the Po $\mathrm{Chu}$ fault, in the northeastern part of the region, is believed to have caused the 1950 Great Assam Earthquake of Mw 8.7 (BenMenahem 1974; Thingbaijam et al., 2008). The Shillong plateau has been implicated with a pop-up tectonics associating the 1897 Great Earthquake of $\mathrm{Mw} 8.1$ (Bilham and England 2001). The southern end of the Kopili fault is 
believed to have generated the 1869 Cachar earthquake of MW 7.4. The Indo-Myanmar arc, sidelined by Patkoi-Naga-Manipur-Chin hills, has been associated with 1988 Manipur Earthquake of Mw 7.2. Overall, seismic activities in the region have been quite significant.

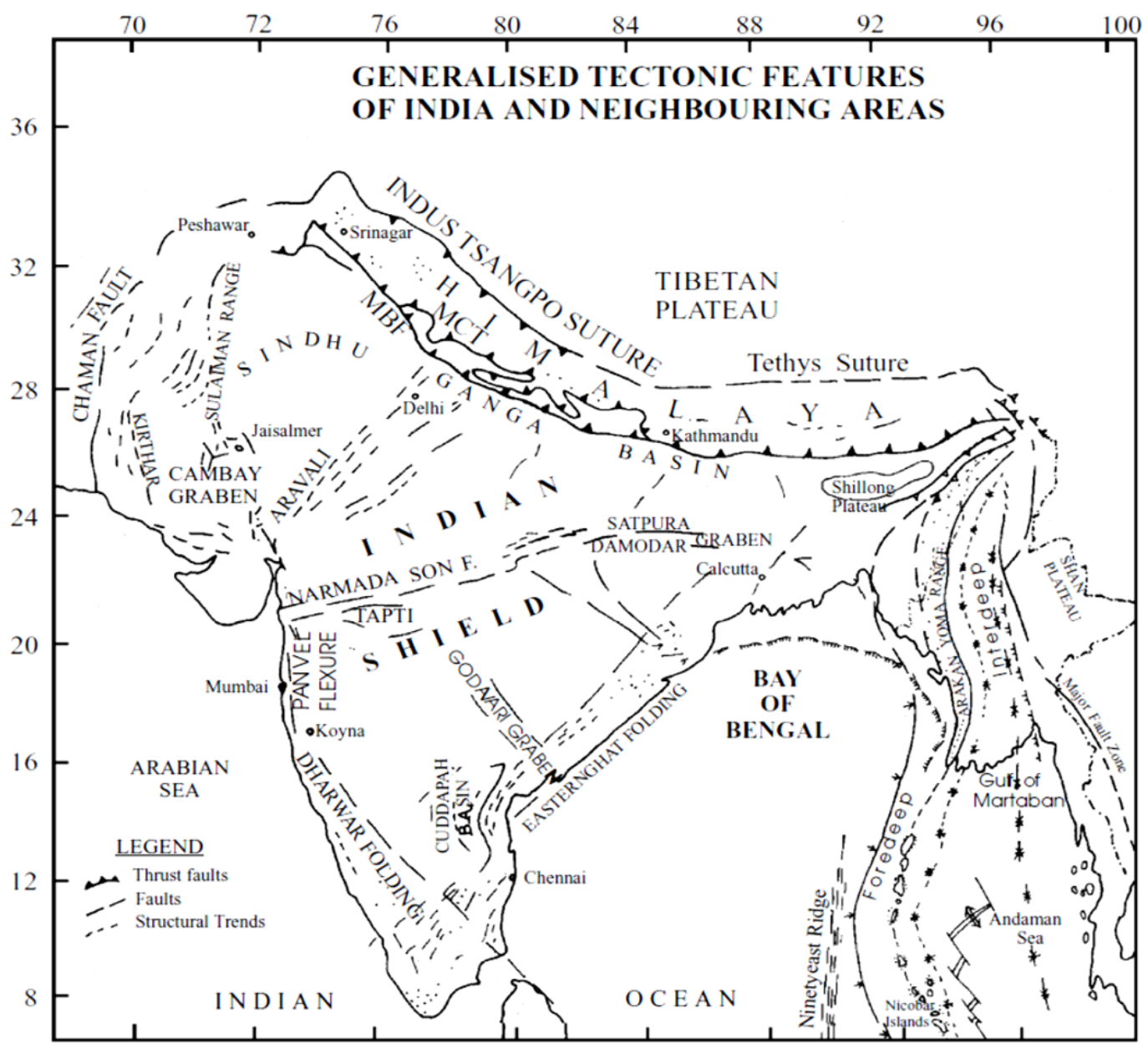

Figure 1. Generalized tectonic map of India and adjacent areas (Parvez et al., 2008)

\section{Acceleration Data}

Two types of data sets collected from the region of the Garhwal and Kumaon Himalaya have been used in the study. These data sets are briefly described in the following paragraphs:

The first data set 111 records from 7 earthquakes $(5.2 \leq \mathrm{M} \leq 6.8)$ as shown in figure 2 became available from the deployment of a strong motion array comprised of strong motion accelerographs (SMA-1 of Kinematrics) in the NE Himalaya for the purpose of measuring the strong ground motion due to moderate and large-sized earthquakes occurring in the region (Chandrasekaran, 1991). At each station, the threshold level (trigger level) to sense the ground motion was set about $0.01 \mathrm{~g}$. 
The analog recordings of these earthquakes were manually digitized using a semiautomatic digitizer and digital data was processed adopting standard processing procedures (Trifunac, 1976). The data was converted to a uniform sampling rate of 0.02 seconds and band-pass filtered $(0.17-0.20 \mathrm{~Hz} ; 25-27$ $\mathrm{Hz}$ ) using an Ormsby filter (Chandrasekaran and Das, 1992).

The second data set of 105 records from 17 earthquakes of magnitude range $(4.0 \leq \mathrm{M} \leq 6.8)$ was recorded by recently installed digital accelerographs (Figure 3) in the North-East Himalaya. These accelerograph installations form part of the National Strong Motion Network of 300 strong motion stations deployed under Mission Mode project to cover seismic zones $\mathrm{V}$, IV and some thickly populated cities falling in seismic zone III (Kumar et al., 2012; Mittal et al., 2012). The digital accelerographs are of GSR-18 type (Geosig, model GSR-18) and data is acquired at a sampling rate of 200 Hz. About 260 digital accelerographs, networked using NIC-net allows monitoring the health of accelerographs as well as downloading of the strong motion data at IIT Roorkee campus.

The earthquakes considered for attenuation regression are shown in Table 1.

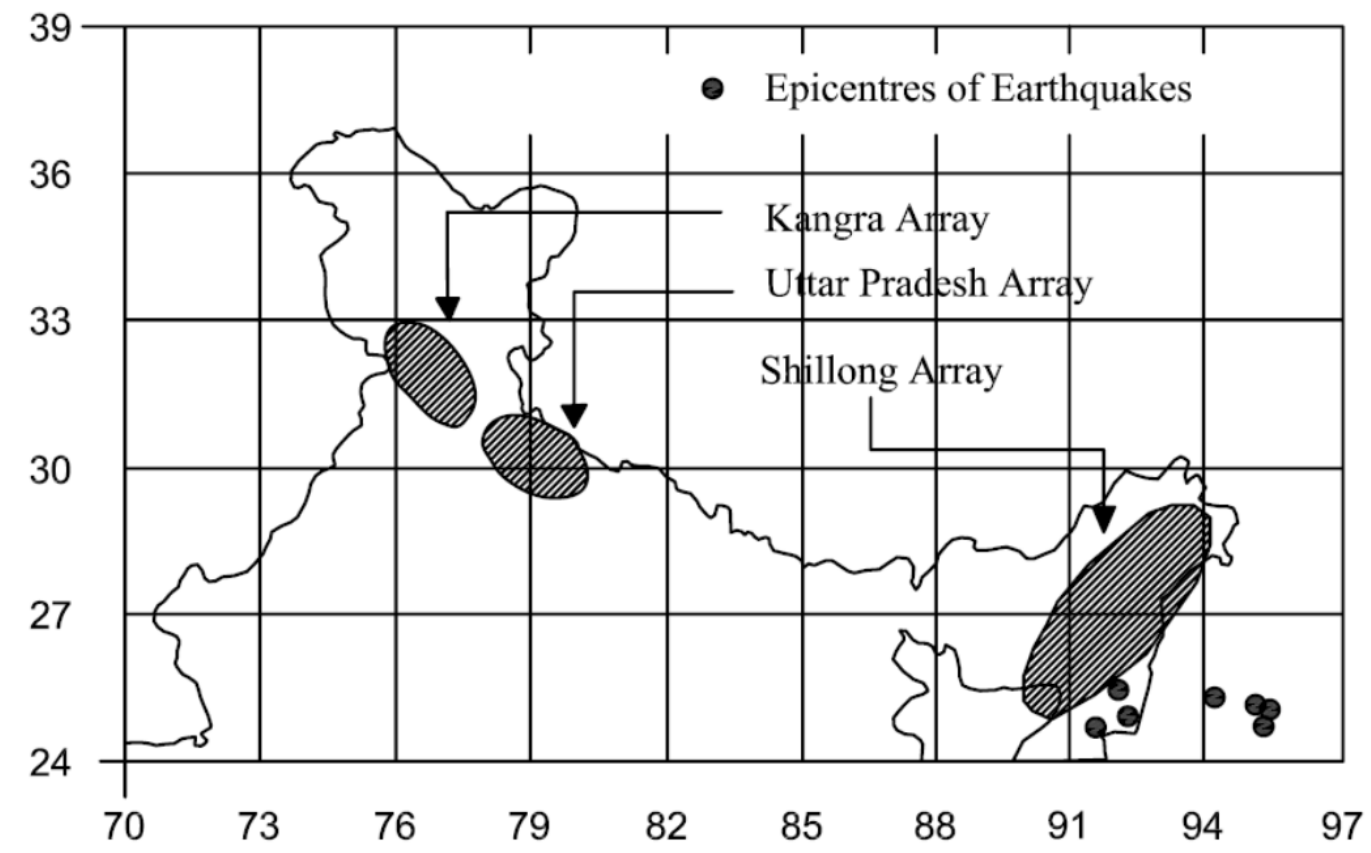

Figure 2. Map showing the strong motion arrays and locations of earthquakes (Sharma, 2005)

\section{Attenuation Relationship}

The development of attenuation relations for the peak ground acceleration have been well explained by the authors e.g. Boore and Joyner (1982), Campbell (1985), Tanaka and
Fukushima (1987), Joyner and Boore (1988), Abrahamson and Litehiser (1989), Fukushima and Tanaka (1990) and Sharma (1998). In general form, the attenuation relation is considered as:

$\log (a)=f_{1}(M)+f_{2}(r, E)+f_{3}(r, m, E)+f_{4}(F)+\varepsilon$ 


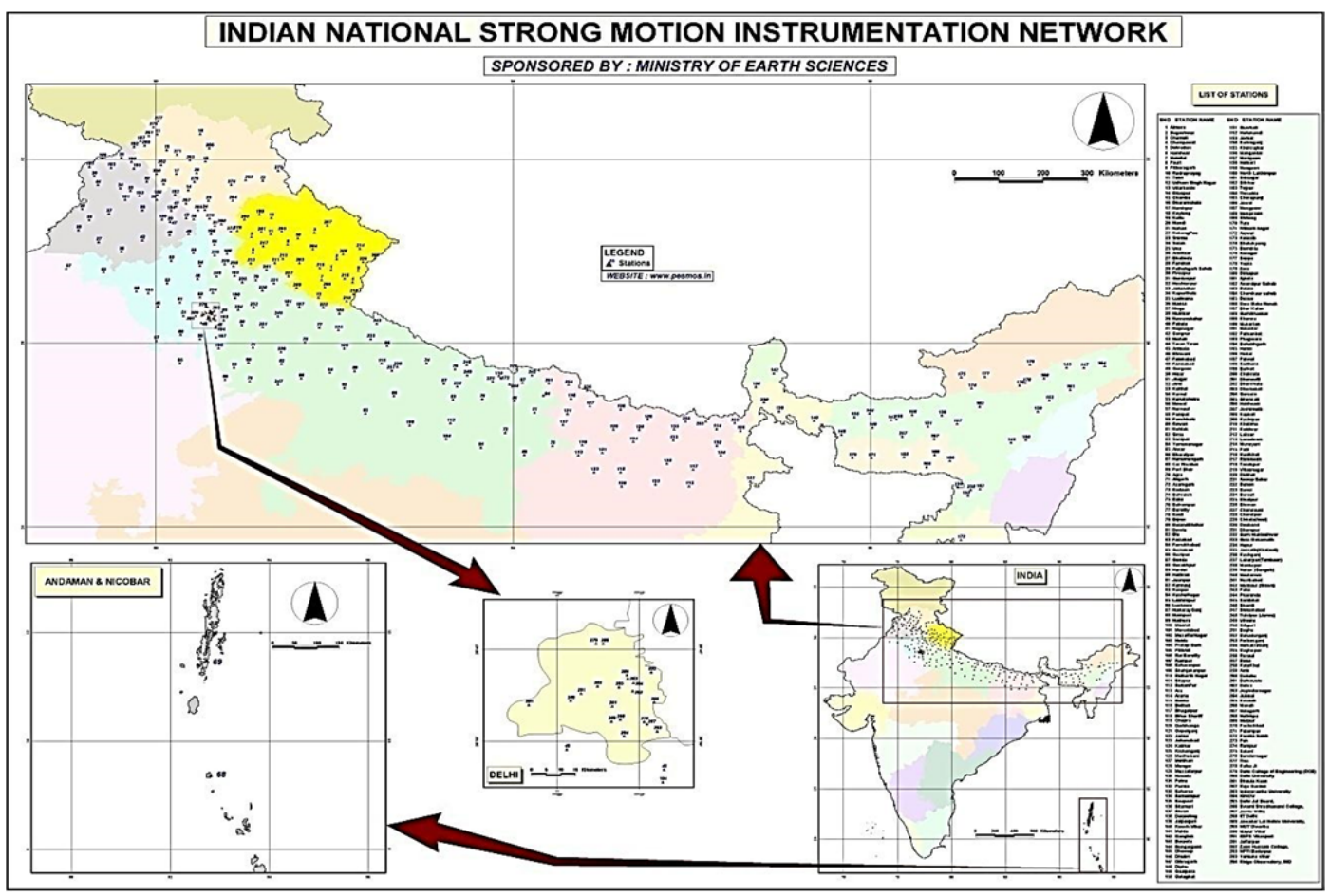

Figure 3. Indian nation strong motion instrumentation network (Kumar et al., 2012)

Table 1. The earthquakes considered for attenuation regression analysis

\begin{tabular}{|c|c|c|c|c|c|c|c|}
\hline Earthquake & Date & Time & Latitude $\left({ }^{\circ} \mathrm{N}\right)$ & Longitude $\left({ }^{\circ} \mathrm{E}\right)$ & Depth $(\mathrm{Km})$ & Magnitude & Records \\
\hline 1 & 19860910 & $13: 20$ & 25.43 & 92.08 & 43 & 5.2 & 12 \\
\hline 2 & 19870518 & $07: 24$ & 25.27 & 94.20 & 50 & 5.7 & 14 \\
\hline 3 & 19880206 & $20: 21$ & 24.65 & 91.52 & 15 & 5.8 & 18 \\
\hline 4 & 19880806 & 06:07 & 25.15 & 95.13 & 91 & 6.8 & 33 \\
\hline 5 & 19900110 & $00: 21$ & 24.75 & 95.24 & 119 & 6.1 & 14 \\
\hline 6 & 19950506 & $07: 29$ & 25.01 & 95.34 & 122 & 6.4 & 9 \\
\hline 7 & 19970805 & $08: 23$ & 24.89 & 92.25 & 35 & 5.6 & 11 \\
\hline 8 & 20090215 & $07: 35$ & 26.00 & 90.20 & 39.3 & 4.4 & 5 \\
\hline 9 & 20090224 & $17: 46$ & 25.90 & 94.30 & 10 & 4.8 & 5 \\
\hline 10 & 20090425 & 04:04 & 30.60 & 79.30 & 10 & 4.0 & 2 \\
\hline 11 & 20090819 & $10: 45$ & 26.60 & 92.50 & 20 & 4.9 & 2 \\
\hline 12 & 20090830 & $19: 27$ & 25.40 & 94.80 & 85 & 5.3 & 5 \\
\hline 13 & 20090903 & 19:51 & 24.30 & 94.60 & 100 & 5.9 & 9 \\
\hline 14 & 20090921 & 08:53 & 27.30 & 91.50 & 8 & 6.2 & 14 \\
\hline 15 & 20091029 & $17: 00$ & 27.30 & 91.40 & 10 & 4.2 & 5 \\
\hline 16 & 20091029 & $19: 56$ & 26.60 & 90.00 & 5 & 5.2 & 5 \\
\hline 17 & 20091108 & $21: 43$ & 24.40 & 94.80 & 22 & 5.6 & 12 \\
\hline 18 & 20091229 & 09:01 & 24.50 & 94.80 & 80 & 5.5 & 6 \\
\hline 19 & 20091231 & 09:57 & 27.30 & 91.40 & 7 & 5.5 & 5 \\
\hline 20 & 20100226 & 04:42 & 28.50 & 86.70 & 28 & 5.4 & 7 \\
\hline 21 & 20100911 & 07:02 & 25.90 & 90.20 & 20 & 5.0 & 3 \\
\hline 22 & 20101212 & $01: 40$ & 25.00 & 93.30 & 15 & 4.8 & 2 \\
\hline 23 & 20110204 & $13: 53$ & 28.40 & 94.60 & 30 & 6.4 & 7 \\
\hline 24 & 20110918 & $12: 40$ & 27.70 & 88.20 & 10 & 6.8 & 13 \\
\hline
\end{tabular}


where ' $a$ ' represents peak ground acceleration $(\mathrm{PGA}) ; \mathrm{fl}(\mathrm{M})$ is a function of earthquake magnitude; $f 2$ (r, E) is a function of earthquake-to-recording site distance and the tectonic environment; f3 ( $r, \mathrm{M}, \mathrm{E})$ is a nonseparable function of magnitude, distance, and tectonic environment; $\mathrm{f} 4 \mathrm{~F}$ ) is a function of fault type; and $\varepsilon$ is a random variable that represents uncertainty in $\log$ (a). Joyner and Boore (1981) used fl (M), f2 (r, E), and f4 (F) assuming that the distance and magnitude have the separable influence on peak ground motion. Campbell (1981) used f1 (M), f3 (r, $\mathrm{M}, \mathrm{E})$, and $\mathrm{f} 4(\mathrm{~F})$ considering distance and magnitude have a non-separable effect on peak ground motion. While Abrahamson and Litehiser (1989) used a hybrid model of Campbell and Joyner and Boore. Campbell (1985) discussed the functional form $\mathrm{fl}(\mathrm{M})$, f2 (r, E), f3 (r, M, E), and f4 (F). In this study, the same type of functional form has been considered for regression analysis. The magnitude-distance distribution of peak ground horizontal accelerations is shown in Figure 4.

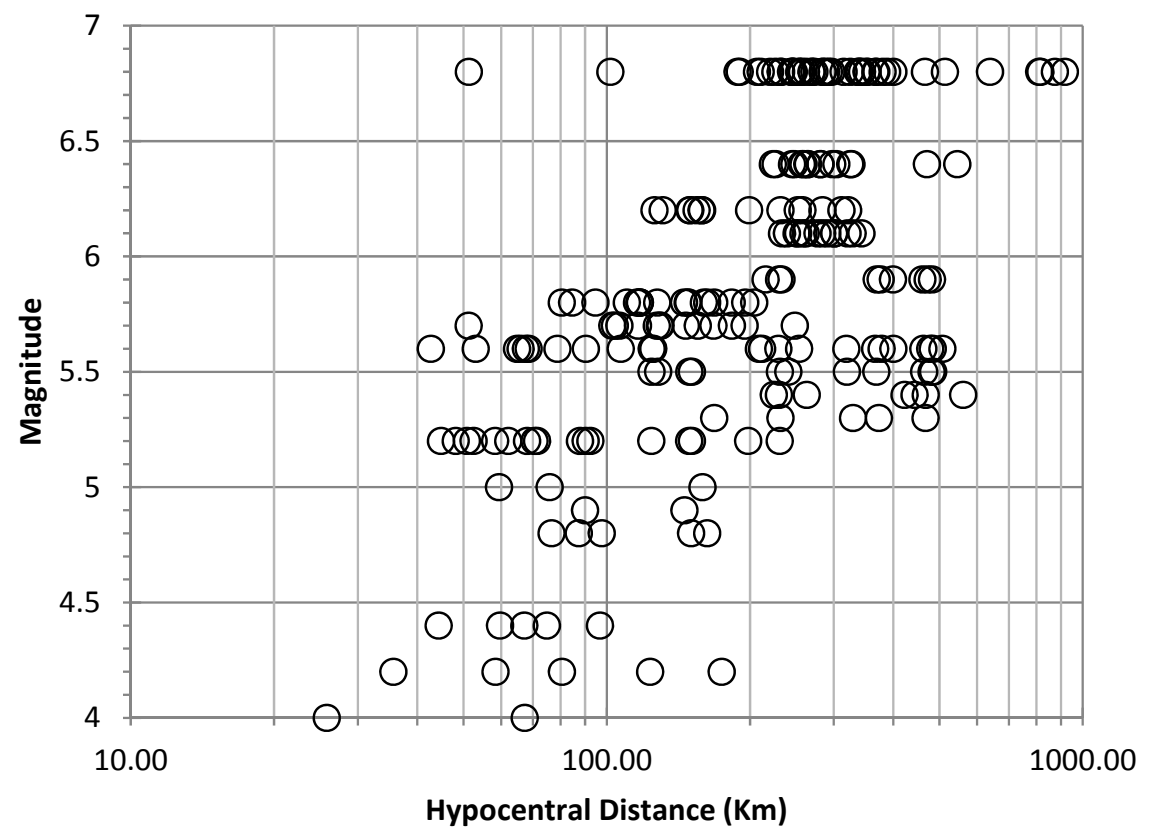

Figure 4. The magnitude-distance distribution of peak ground horizontal accelerations

First of all, a linear regression analysis had been carried out considering a simple relation as:

$$
\log (\mathrm{A})=-b \log (\mathrm{X})+\mathrm{c}
$$

where $\mathrm{A}$ is the peak ground acceleration, $\mathrm{X}$ is the hypocentral distance, and $\mathrm{b}$ and $\mathrm{c}$ are the regression coefficients. The results for each earthquake have been shown in Table 2.

The estimated average value of the decay parameter ' $b$ ' is 1.20 . The value by consider- ing the whole that set $0.55 \pm 0.11$, which is very small as compared to the average value from individual earthquakes. Fukushima and Tanaka (1990) well illustrated this phenomenon while considering the actual recordings as well as the synthetic data using numerical experiments. Two-step stratified regression analysis has been used by Fukushima and Tanaka (1990) to overcome this effect. Joyner and Boore (1988) adopted the same method to 
avoid the interaction of b-value estimates. In this study, the same method is applied here:

$$
\log (A)=-b \log (X)+\sum d_{i} l_{i}
$$

Table 2. The values of regression coefficients for each earthquakes

\begin{tabular}{|c|c|c|}
\hline Earthquake & 'b' value & Coefficient 'c' \\
\hline 1 & $1.068 \pm 0.396$ & $3.693 \pm 0.689$ \\
\hline 2 & $1.007 \pm 0.252$ & $3.814 \pm 0.536$ \\
\hline 3 & $0.836 \pm 0.551$ & $3.430 \pm 1.173$ \\
\hline 4 & $1.200 \pm 0.476$ & $4.964 \pm 1.168$ \\
\hline 5 & $1.469 \pm 0.958$ & $5.427 \pm 2.345$ \\
\hline 6 & $4.794 \pm 1.396$ & $3.324 \pm 3.416$ \\
\hline 7 & $0.810 \pm 0.373$ & $3.464 \pm 0.704$ \\
\hline 8 & $1.995 \pm 0.886$ & $4.699 \pm 1.618$ \\
\hline 9 & $0.267 \pm 0.127$ & $1.531 \pm 0.237$ \\
\hline 10 & $0.724 \pm 0.000$ & $1.455 \pm 0.000$ \\
\hline 11 & $1.497 \pm 0.483$ & $6.588 \pm 1.226$ \\
\hline 12 & $1.015 \pm 0.598$ & $3.495 \pm 0.479$ \\
\hline 13 & $0.682 \pm 0.578$ & $2.672 \pm 1.469$ \\
\hline 14 & $0.682 \pm 0.578$ & $2.672 \pm 1.469$ \\
\hline 15 & $1.098 \pm 0.868$ & $1.478 \pm 1.931$ \\
\hline 16 & $1.014 \pm 0.586$ & $1.197 \pm 1.515$ \\
\hline 17 & $0.779 \pm 0.392$ & $2.655 \pm 0.858$ \\
\hline 18 & $0.562 \pm 0.506$ & $2.018 \pm 1.291$ \\
\hline 19 & $1.471 \pm 0.823$ & $4.719 \pm 2.052$ \\
\hline 20 & $1.438 \pm 0.000$ & $4.199 \pm 0.000$ \\
\hline 21 & $0.674 \pm 0.439$ & $2.371 \pm 0.846$ \\
\hline 22 & $0.909 \pm 0.366$ & $2.606 \pm 0.717$ \\
\hline 23 & $1.100 \pm 0.000$ & $1.621 \pm 0.000$ \\
\hline 24 & $1.719 \pm 0.167$ & $5.530 \pm 0.431$ \\
\hline
\end{tabular}

Where di is a coefficient for the ith earthquake and li is equal to 1 for the ith earthquake, and 0 otherwise. The ' $b$ ' value estimated in this way is $1.19 \pm 0.12$, which is close to average ' $b$ ' values estimated from individual earthquakes.

After this, a multiple regression analysis was performed considering whole data between magnitudes and hypocentral distances as

$$
\log (A)=a M-b \log (X)+c
$$

Where $\mathrm{M}$ is the magnitude (Table 1) and a, $\mathrm{b}$, and $\mathrm{c}$ are the regression coefficients. The value of the decay parameter while considering the whole data set came out to be $1.179 \pm 0.098$, which is less than the value estimated by equation 3 , thus in regression analysis, the values $1.19 \pm 0.12$ have been used.
In regression analysis the model as in equation (1), which represents the general form of the attenuation relationship used. The term $\mathrm{f} 4(\mathrm{~F})$ is not considered because only few fault plane solutions for these earthquakes are reported. Similarly, Sharma (1998) derived regression model for Himalayan region neglecting focal mechanism. Abrahamson and Litehiser (1989) derived an attenuation relation in the United States by segregating the data into interplate and intraplate, and they found a very small difference for the two source regions. The regression model thus selected for the attenuation relation, as from equation (1), is considered as follows:

$$
\log (A)=c_{1}+c_{2} M-\operatorname{blog}\left(X+e^{c_{3}}\right)
$$

Where $c_{1}, c_{2}$, and $c_{3}$ are the regression coefficients. The value of ' $b$ ' is fixed to be 1.19 .

The regression analysis gave the values of $\mathrm{c}_{1}=-1.497 \pm 0.3494, \mathrm{c}_{2}=0.3882 \pm 0.1203$ and $c_{3}=0.8579 \pm 0.2341$. The estimated attenuation relationship is as follows:

$\log (A)=-1.497+0.3882 M-1.19\left(X+e^{0.2876 M}\right)$

The residual sum of squares for equation (6) is 0.1451 , which is the sum of the squares of the difference of the observed and predicted peak horizontal accelerations. Earlier attenuation relationship developed for the Himalayan regions are:

$\log (A)=-1.072+0.3903 M-1.21 \log \left(X+e^{0.5873 M}\right)$

(Sharma, 1998)

$\log (A)=0.101 M-0.9258 \log \left(X+e^{0.4562 M}\right)$

(Sharma, 2005)

A comparison of these three relations derived for the Himalayan region is shown in Figure 5. The first relationship by Sharma (1998) was developed using the 66 recordings from 7 earthquakes, in which 5 earthquakes belongs to North-East Himalaya and 2 from North-West Himalaya. The second relationship was developed using 666 recordings from 82 earthquakes from worldwide. The present relationship is more close to Sharma (2005). In the present study, 216 recordings from 24 earthquakes occurred 
Vietnam Journal of Earth Sciences, 39(1), 47-57

in North-East Himalayan region were used, estimation. Attenuation relationship for which will provide better insight for site- magnitudes 5, 6, 7 and 8 for North - East specific studies as well as for hazard Himalayan region are shown in Figure 6.

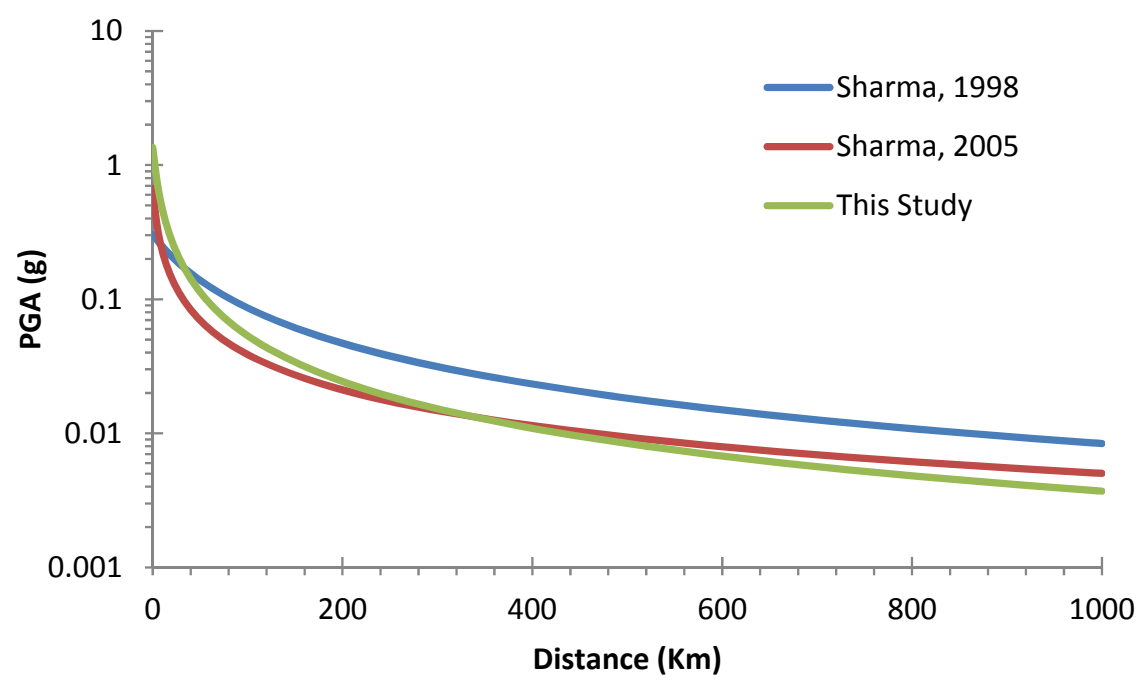

Figure 5. Comparison of Relationships derived for Himalayan region

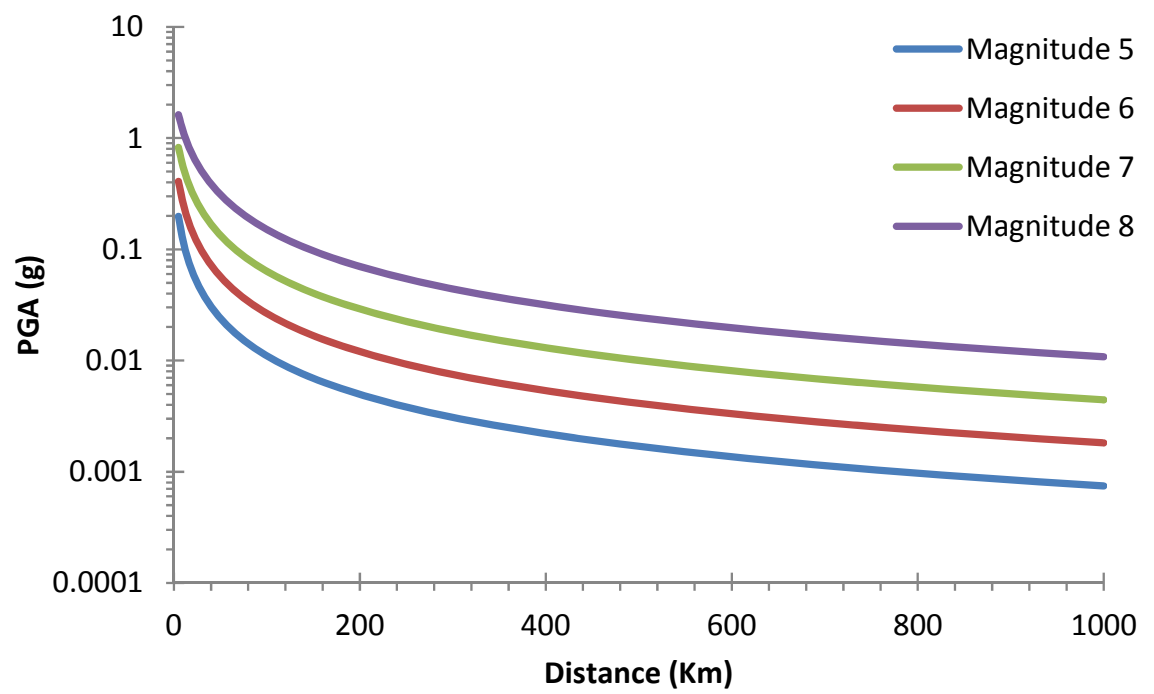

Figure 6. Attenuation relationship for magnitudes 5, 6, 7 and 8 for North-East Himalayan region

\section{Conclusions}

A data set of 216 peak ground horizontal accelerations from 24 earthquakes $(4.0 \leq \mathrm{M} \leq$ 6.8) recorded by strong-motion arrays and $\mathrm{Na}-$ tional Strong Motion Network project have been utilized to develop empirical attenuation relationship for peak ground horizontal acceleration for North-East Himalayan region. Using two-step stratified regression model an at- 
Arjun Kumar, et al./Vietnam Journal of Earth Sciences 39 (2017)

tenuation relationship as given in equation (6) has been developed for the North-East Himalayan region. Which will provide better insight for site-specific studies as well as for hazard estimation. Attenuation relationship for magnitudes 5, 6, 7 and 8 for North-East Himalayan region are presented.

\section{Acknowledgments}

The authors are thankful for the first data set of strong-motion provided by the research scheme "Strong Motion Arrays in India," sponsored by the Department of Science and Technology, Government of India. The authors are also thankful to Ministry of Earth Sciences (MoES) for funding the project under which the second data was collected. The authors sincerely thank Prof. Ashok Kumar and Prof. Ashwani Kumar for their helpful suggestions, advice, and critical comments at various stages of the study.

\section{References}

Abrahamson, N.A., Litchiser, J.J., 1989. Attenuation of vertical peak accelerations. Bulletin of the Seismological Society of America, 79, 549-580.

Aman, A, Singh, U.K., Singh, R.P., 1995. A new empirical relation for strong seismic ground motion for the Himalayan region. Current Science, 69(9), 772-777.

Ambraseys, N.N., Douglas, J., 2003. Near-field horizontal and vertical earthquake ground motions. Soil Dynamics and Earthquake Engineering, 23, $1-18$.

Atkinson, G.M., Boore, D.M., 2003. Empirical groundmotion relations for subduction zone earthquakes and their application to Cascadia and other regions. Bulletin of the Seismological Society of America, 93, 1703-1729.

Ben-Menahem, A., Aboudi, E., Schild, R., 1974. The source of the great Assam earthquake-an intraplate wedge motion. Physics of Earth and Planetary Interior, 9, 265-289.

Bilham, R., England, P., 2001. Plateau 'pop up' in the great 1897 Assam earthquake. Nature, 410, 806-809.
Boore, D.M., Joyner, W.B., 1982. The empirical prediction of ground motion. Bulletin of the Seismological Society of America, 72, 843-860.

Campbell, K.W., 1985. Strong motion attenuation relations: a ten year perspective. Earthquake Spectra, $1,759-803$.

Campbell, K.W., Bozorgnia, Y., 2003. Updated nearsource ground-motion (attenuation) relations for the horizontal and vertical components of peak ground acceleration and acceleration response spectra. Bulletin of the Seismological Society of America, 93, 314-331.

Chandrasekaran, A.R., Das, J.D., 1991. Analysis of strong ground motion accelerograms of Uttarkashi Earthquake of October 20. Department of Earthquake Engineering, Univversity of Roorkee, India Report, EQ: 91-10.

Chandrasekaran, A.R., Das, J.D., 1992. Strong motion arrays in India and analysis of data from Shillong array, Current Science, 62, 233-250.

Dewey, J.F., Bird, J.M., 1970. Mountain belts and the new global tectonics. Journal of Geophysical Research, 75, 2625-2647.

Douglas, J., 2001. A comprehensive worldwide summary of strong-motion attenuation relationships for peak ground acceleration and spectral ordinates (1969 - 2000). ESEE Report 01-1, Department of Civil and Environmental Engineering, Imperial College, London.

Fukushima, Y., Tanaka, T., 1990. A new attenuation relation for peak horizontal acceleration of strong earthquake ground motion in Japan. Bulletin of the Seismological Society of America, 80, 757-783.

Fukushima, Y., Berge-Thierry, C., Volant, P., GriotPommera, D.A., Cotton, F., 2003. Attenuation relation for West Eurasia determined with recent near-fault records from California, Japan and Turkey. Journal of Earthquake Engineering, 7(4), 573-598.

IS1893 (Part 1) 2002. Indian standard criteria for earthquake resistant design of structures, part 1, general provisions and buildings (Fifth Revision). Bureau of Indian Standards, New Delhi 110002, 42.

Iyengar, R.N., Ghosh, S., 2004. Microzonation of earthquake hazard in Greater Delhi area; Current Science, 87, 1193-1202.

Jain, S.K., Roshan, A.D., Arlekar, J.N., Basu, P.C., 2000. Empirical attenuation relationships for the Himalayan earthquakes based on Indian strong 
Vietnam Journal of Earth Sciences, 39(1), 47-57

motion data. Proceedings of the Sixth International Conference on Seismic Zonation.

Joyner, W.B., Boore, D.M., 1988. Measurement, characterisation, and prediction of strong ground motion. Proceeding of Earthquake Engineering and Soil Dynamics I1 GT Div/ASCE, Utah, 43-102.

Kayal, J.R., 1987. Microseismicity and source mechanism study: Shillong Plateau, Northeast India. Bulletin of the Seismological Society of America, 77, 184-194.

Kayal, J.R., 1996. Earthquake source processes in northeast India: a review. Journal of Himalayan Geology, 17, 53-69.

Kayal, J. R., 1998. Seismicity of northeast India and surroundings-development over the past 100 years. Journal of Geophysics, XIX, 9-34.

Khattri, K.N., Rogers, A.M., Perkins, D.M, Algermissen, S.T., 1984. A seismic hazard map of India and adjacent areas. Tectonophysics, 108, 93-134.

Kramer, S. L., 1996. Geotechnical earthquake engineering. Pearson Education India.

Kumar, A., Mittal, H., Sachdeva, R., Kumar, A., 2012. Indian strong motion instrumentation network. Seismological Research Letters, 83(1), 59-66.

Kumar, A., Kumar, A., Mittal, H., Kumar, A., Bhardwaj, R., 2012. Software to Estimate Earthquake Spectral and Source Parameters. International Journal of Geosciences, 3(5), 1142-1149.

Kumar, A., Kumar, A., Gupta, S.C., Mittal, H., Kumar, R., 2013a. Source parameters and $f_{\max }$ in Kameng region of Arunachal Lesser Himalaya. Journal of Asian Earth Sciences, 70-71, 35-44.

Kumar, R., Gupta, S.C., Kumar, A., Mittal, H., 2013 b. Source parameters and $f_{\max }$ in lower Siang region of Arunachal lesser Himalaya. Arabian Journal of Geosciences, DOI 10.1007/s12517-013-1223-8.

Mittal, H., Kumar, A., Ramhmachhuani, R., 2012. Indian National Strong Motion Instrumentation Network and Site Characterization of Its Stations. International Journal of Geosciences, 3(6), 1151-1167.

Mukhopadhyay, M., 1984. Seismotectonics of transverse lineaments in the eastern Himalaya and foredeep, Tectonophysics, 109, 227-240.
Nandy, D.R., 2001. Geodynamics of northeastern India and the adjoining region. acb Publication, Calcutta.

Nath, S.K., Thingbaijam, K.K.S., Maiti, S.K., Nayak, A., 2012. Ground-motion predictions in Shillong region, northeast India. Journal of Seismology, 16(3), 475-488.

Parvez, I.A., Sutar, A.K., Mridula, M., Mishra, S.K., Rai, S.S., 2008. Coda Q estimates in the Andaman Islands using local earthquakes. Pure and Applied Geophysics, 165(9-10), 1861-1878.

Raghukanth, S.T.G., Kavitha, B., 2014. Ground motion relations for active regions in India. Pure and Applied Geophysics, 171(9), 2241-2275.

Sharma, M.L., 1998. Attenuation relationship for estimation of peak ground horizontal acceleration using data from Strong-Motion Arrays in India. Bulletin of the Seismological Society of America, 88(4), 1063-1069.

Sharma, M.L., 2005. A new empirical attenuation relationship for peak ground horizontal acceleration for Himalayan region using Indian and worldwide data set. Journal of Geophysics, 26(3), 151-158.

Singh, R.P., Aman, A., Prasad, Y.J.J., 1996. Attenuation relations for strong seismic ground motion in the Himalayan region. Pure and Applied Geophysics, 147(1), 161-180.

Sun, F., Peng, K., 1993. Attenuation of strong ground motion in western U.S.A. Earthquake Research in China, 7(1), 119-131.

Thingbaijam, K.K.S., Nath, S.K., Yadav, A., Raj, A., Walling, M.Y., Mohanty, W.K., 2008. Recent seismicity in northeast India and its adjoining region. Journal of Seismology, 12(1), 107-123.

Trifunac, M.D., 1976. Preliminary analysis of the peaks of strong earthquake ground motion - dependence of peaks on earthquake magnitude, epicentral distance, and recording site conditions. Bulletin of the Seismological Society of America, 66(1), 189-219.

Verma, R.K., Mukhopadhyay, M., Ahluwalia, M.S., 1976. Seismicity, gravity and tectonics of Northeast India and Northern Burma. Bulletin of the Seismological Society of America, 66, 1683-1694. 